\title{
EDITORIAL
}

\section{The prediction of suicide and the law on abortion}

\author{
Michael J Kelleher, MD, MPhil, BSc, FRCPsych, FRCPI, Clinical Director, St. Anne’s Hospital, Shanakiel, Cork, Ireland.
}

In its judgement of the X Case the Supreme Court on March 5th 1992 decided by a majority of 4 to 1 , under Heading 4 that the "Constitution required that termination of pregnancy was permissible only when it was established as a matter of probability that there was a real and substantial risk to the life of the mother if such termination were not effected". By the same majority under Heading 5 it adjudged that the "risks to the life of the mother which should be considered by the Court included a real and substantial risk that the mother might commit suicide" (l). This judgement depends on the "probability that there was a real and substantial risk to the life of the mother" and following from this the ability of medical men and other expert witnesses to establish such a probability.

Broadly speaking medicine uses the concept of probability in several diverse ways such as cause (the Tubercle Bacillus and Tuberculosis), criterion of illness (constricting chest pain and angina), and predictor of future ill-health (high blood pressure and the likelihood of stroke). It is accepted in other areas of science that accurate prediction is difficult if not impossible. This is so in micro-physics as summarised by Heisenberg's, Principle of Uncertainty (2) and also so in macro-physics such as world weather prediction according to the principles of Chaos theory (3). The point has also been made by the great philosopher of science (Popper 1964) (4) that the previous history of a society cannot be the basis of future predictions according to any universal principles.

Traditionally medicine bases prediction, or prognosis, on accurate diagnosis. The function of a diagnosis is to separate the sufferers of a condition from the non-sufferers and thereby to create testable hypotheses concerning cause, treatment and outcome (5). Because of problems of diagnosis and classification of mental disorders, in particular their unreliability, the WHO since the early 1960 's has been engaged in a series of cross national studies and meetings aimed at improving the standardisation of psychological states (6). A diagnosis is regarded as valid if it meets the minimum criteria of the International Classification of Diseases. Reliability, even if improved overall, remains a problem however. It is never absolute.

The International Classification of Diseases has no category referring to suicide, attempted suicide, selfpoisoning, deliberate self-harm or para-suicide. It does readily offer categorisation of other conditions which are clearly not diseases such as fire-setting (F 63 1) fatigue syndrome ( $F$ 48. 0 ) and compulsive gambling (F 63.0). The consequences of this failure is that definitions of suicide and suicidal behaviour are not specified accord- ing to international criteria and therefore reliability is likely to be reduced. Obviously, this lack of reliability is important if suicidal behaviour is to be used as a criterion for allowing termination of pregnancy.

The most thorough assessment of our ability to predict suicide was carried out by Pokorny (7). He followed up 4,800 patients who had been admitted to Houston Veterans Administration Medical Centre, for a period of 4-6 years. Using the best possible clinical predictors of suicide (which included history of suicide attempt, diagnosis of affective disorder or schizophrenia, having been on a suicidal list at any VA Hospital, being single, widowed or divorced), he correctly identified 35 of the 63 who took their lives five years later. This however, was at a cost of wrongly predicting 1,206 cases. In other words the predictive value of his criteria, which were the best clinically available, was only $2.8 \%$. Bringing this to whole numbers for every 100 cases of suicide predicted the prophecy was wrong 97 times.

Leaving matters of definition and unreliability aside there are two great difficulties in predicting suicide. Firstly it is a rare event and in all rare events the greatest likelihood is that the event will not occur. In Ireland the suicide rate is approximately 10 per 100,000 or 1 per 10,000 population per annum. If the rate was to increase a thousand times it would still be only 1 in 10 which is still a matter of low probability (8).

Secondly, in predicting suicide one is making at least two judgements, firstly that the individual belongs to a particular clinical category and secondly that the likelihood of suicide within that category is of a certain order. In depression $15 \%$ eventually commit suicide (9). This is similar to the lifetime risk of suicide given for nonfatal suicide attempters (10). A similar likelihood of lifetime risk of suicide (18\%) has been given for alcoholics (11). Substance abuse is also associated with a higher risk of suicide (12). In schizophrenia the lifetime risk of suicide is approximately $10 \%$ (13). However, in all these categories of illness the greatest likelihood is non-suicide. Social criteria such as marital and occupational status, race, religious belief and social class have a much lower predictive value as does age and gender even though each carries some weight. Furthermore the social characteristics of suicide vary over space and time e.g., the main increase in suicide in Ireland in recent times has been amongst the young and middle-aged men (14) but this may change with changing circumstances.

It was held by the Supreme Court in the X Case "that the risks to the life of the mother ... included a real and substantial risk that the mother might commit suicide". The research evidence, quoted above, indicates that 
medicine and psychology does not have the ability to predict suicide, even with a moderate degree of accuracy. This is not to say that there may not be medical or psychological grounds for which termination of pregnancy may be allowed within the State at some future date either through Legislative or Constitutional means.

\section{References}

1. Attorney General, Plaintiff versus $X$ and other defendants (1992) No. 846 P, Irish Law Reports.

2. Hawking SW. A Brief history of time. London: Bantam Press, 1992: 54.

3. Gleick J. Chaos: making a new science. London: Sphere Books, $1991 ; 16$.

4. Popper K. The poverty of historicism. New York: Harper \& Row, 1964

5. Wing JK. Methodological issues in psychiatric case identification. Psychol Med 1980; 10(1): 5-10.
6. Sartorius N. Preface 2 ICD 10: classification of mental and behavioural disorders. Geneva: WHO, 1992.

7. Pokorny AD. Prediction of suicide in psychiatric patients: report of a prospective study. ArchGen Psychiatry 1983; 40: 249-57.

8. Maris RW. Overview of the study of suicide. In: Maris RW, Berman AL, Maltsberger JT, Yufit RI, editors. Assessment and prediction of suicide. New York: Guildford Publications, 1992: 8 .

9. Black DW, Winokur G. Prospective studies of suicide and mortality in psychiatric patients. Ann N Y Acad Sci 1986; 487 : 106-13

10. Maris RW. Pathways to suicide: a survey of self-destructive behaviours. Baltimore MD: John Hopskins University, 1982.

11. Roy A, Linnoila N. Alcoholism and suicide. Suicide and Life Threatening Behaviour 1986; 16:214-73

12. Bagley C. Profiles of youthful suicides. Psychol Rep 1989; 65: 234.

13. Morgan HG, Owen JH. Persons at risk of suicide: Guidelines on good Clinical Practice - Page 34

14. Kelleher MJ, Daly M. Suicide in Cork and Ireland. Br J Psychiatry 1990; 157: 533-8.

Editor-in-Chief: Brian Lawlor (Dublin). Editors: Timothy Dinan (London), David King (Belfast). Deputy Editor: Brian O'Shea (Dublin). Associate Editors: Ken Brown (Belfast), Patricia Casey (Dublin), Anthony Clare (Dublin), Stephen Cooper (Belfast), Thomas Fahy (Galway), Michael Fitzgerald (Dublin), Michael Kelleher (Cork), Brian Leonard (Galway), Roy McClelland (Belfast), Aidan McGennis (Dublin), Ciaran O'Boyle (Dublin), Eadbhard O'Callaghan (Dublin), Art O'Connor (Dublin), Ethna O'Gorman (Belfast), lan Pullen (Edinburgh), David Sheehan (Tampa), Philip Snaith (Leeds), Hugh Staunton (Dublin), John Waddington (Dublin), Richard Williams (Calgary). Statistical Editor: Leslie Daly (Dublin). Deputy Statistical Editor: Ronan Conroy (Dublin).

\section{The John Dunne Medal}

The John Dunne Medal is awarded annually by the Irish Journal of Psychological Medicine. Trainees from Ireland, Northern Ireland, and Great Britain are eligible. The trainee shall have contributed substantially, though not necessarily as the first author, to an original paper (exceptionally an article in another category) published by the Journal in the previous year.

The bronze medal is named after Dr John Dunne, the first psychiatry professor in Ireland, and the president, in 1955, of the Royal Medico-Psychological Association. The bronze medal was sculpted by Robin Buick, ARHA. It has been exhibited by the Royal Hibernian Academy.

The international panel of adjudicators selects the medal winner on the basis of the paper's

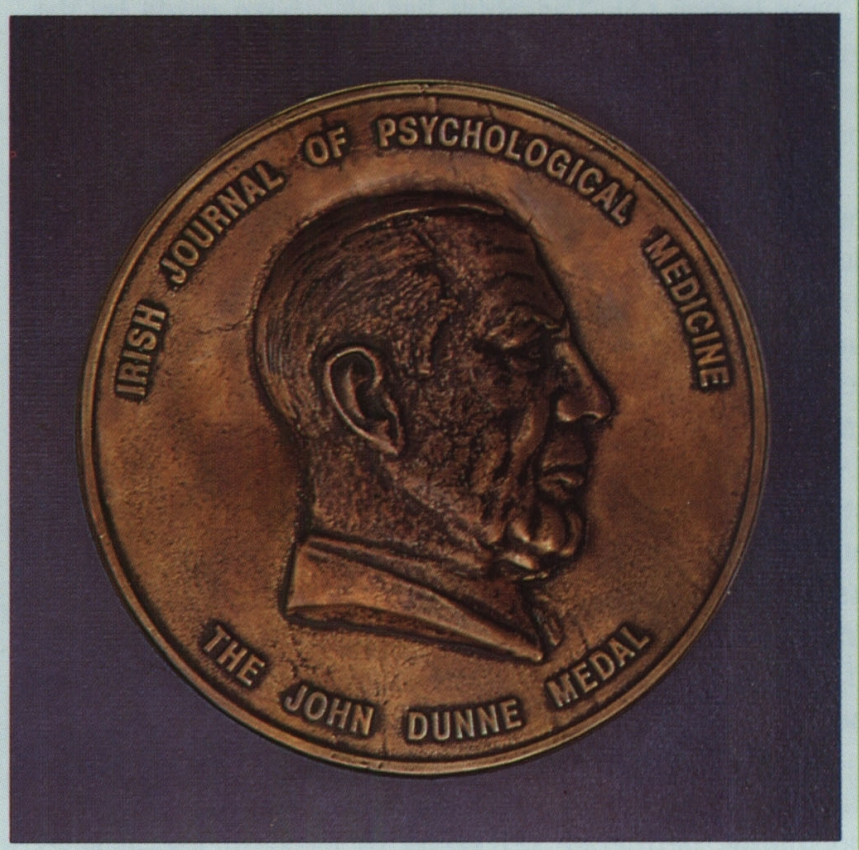
originality, method, and relevance for future research or clinical practice. The first authors of articles published in October '93, March '94, June '94, and September '94 are invited to submit a trainee's name into the competition for the 1994 prize. The winner will be announced in the December '94 issue. 